\title{
Measured and modelled sublimation on the tropical Glaciar Artesonraju, Perú
}

\author{
M. Winkler ${ }^{1}$, I. Juen ${ }^{1}$, T. Mölg ${ }^{1}$, P. Wagnon ${ }^{2}$, J. Gómez ${ }^{3}$, and G. Kaser ${ }^{1}$ \\ ${ }^{1}$ Tropical Glaciology Group, Faculty of Geo- and Atmospheric Sciences, University of Innsbruck, Innrain 52, \\ 6020 Innsbruck, Austria \\ ${ }^{2}$ IRD Great Ice, Laboratoire de Glaciologie et Geóphysique de l'Environnement, Saint Martin d'Hères, France \\ ${ }^{3}$ Unidad de Glaciología y Recursos Hídricos, Huaráz, Perú
}

Received: 18 July 2008 - Published in The Cryosphere Discuss.: 8 September 2008

Revised: 17 December 2008 - Accepted: 19 December 2008 - Published: 9 February 2009

\begin{abstract}
Sublimation plays a decisive role in the surface energy and mass balance of tropical glaciers. During the dry season (May-September) low specific humidity and high surface roughness favour the direct transition from ice to vapour and drastically reduce the energy available for melting. However, field measurements are scarce and little is known about the performance of sublimation parameterisations in glacier mass balance and runoff models.

During 15 days in August 2005 sublimation was measured on the tongue of Glaciar Artesonraju $\left(8^{\circ} 58^{\prime} \mathrm{S}, 77^{\circ} 38^{\prime} \mathrm{W}\right)$ in the Cordillera Blanca, Perú, using simple lysimeters. Indicating a strong dependence on surface roughness, daily totals of sublimation range from $1-3 \mathrm{~kg} \mathrm{~m}^{-2}$ for smooth to $2-$ $5 \mathrm{~kg} \mathrm{~m}^{-2}$ for rough conditions. (The 15 -day means at that time of wind speed and specific humidity were $4.3 \mathrm{~m} \mathrm{~s}^{-1}$ and $3.8 \mathrm{~g} \mathrm{~kg}^{-1}$, respectively.)

Measured sublimation was related to characteristic surface roughness lengths for momentum $\left(z_{m}\right)$ and for the scalar quantities of temperature and water vapour $\left(z_{s}\right)$, using a process-based mass balance model. Input data were provided by automatic weather stations, situated on the glacier tongue at $4750 \mathrm{~m}$ a.s.1. and $4810 \mathrm{~m}$ a.s.1., respectively. Under smooth conditions the combination $z_{m}=2.0 \mathrm{~mm}$ and $z_{s}=1.0 \mathrm{~mm}$ appeared to be most appropriate, for rough conditions $z_{m}=20.0 \mathrm{~mm}$ and $z_{s}=10.0 \mathrm{~mm}$ fitted best.

Extending the sublimation record from April 2004 to December 2005 with the process-based model confirms, that sublimation shows a clear seasonality. 60-90\% of the energy available for ablation is consumed by sublimation in the dry season, but only $10-15 \%$ in the wet season (October-April).
\end{abstract}

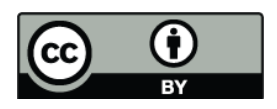

Correspondence to: $\mathrm{M}$. Winkler (michael.winkler@uibk.ac.at)
The findings are finally used to evaluate the parameterisation of sublimation in the lower-complexity mass balance model ITGG, which has the advantage of requiring precipitation and air temperature as only input data. It turns out that the implementation of mean wind speed is a possible improvement for the representation of sublimation in the ITGG model.

\section{Introduction}

Tropical glacier mass balances provide valuable information about climate and climate change in tropical mountain regions, where long-term climate data is scarce. Tropical climate is controlled by hygric seasonality and not by annual temperature cycles, as in the mid- and high latitudes. Since the mass balance of tropical glaciers is very sensitive to shifts in hygric conditions, they are suitable proxies for tropical climate change beyond the air temperature view (Kaser, 2001; Kaser and Osmaston, 2002). The mountain range of the Cordillera Blanca, Perú, harbours about one quarter of the area of all tropical glaciers (Kaser, 1999). Hence, a greater knowledge of the glacier mass balance signal in the Cordillera Blanca is vital to understand climate impacts on tropical glaciers.

The specific net mass balance of a point on the glacier surface is defined as the sum of accumulation and ablation. Accumulation is controlled mainly by local solid precipitation, the ablation processes are governed by the surface energy balance (e.g. Hoinkes, 1970; Kuhn, 1989). Wind drift, avalanches and calving processes may also contribute but are neglected for this paper. The surface energy balance is the

Published by Copernicus Publications on behalf of the European Geosciences Union. 


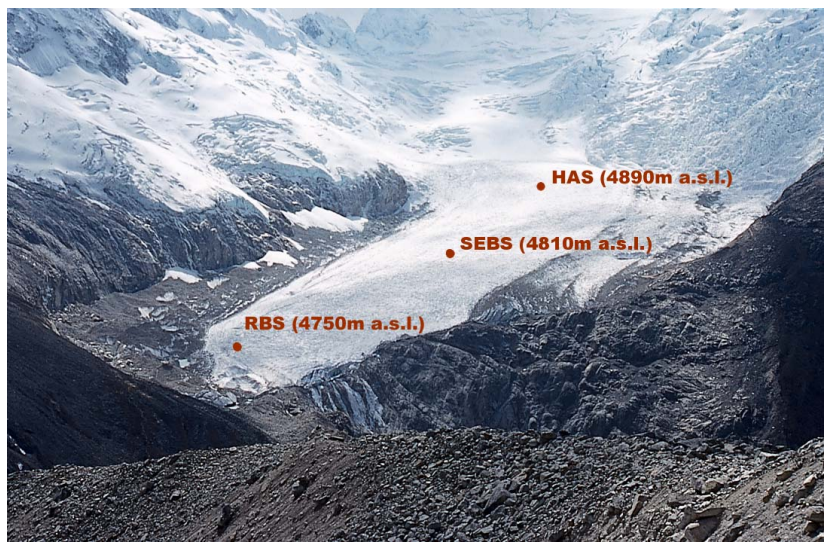

Fig. 1. This picture of the tongue of Glaciar Artesonraju was taken by M. Winkler in August 2005. The red dots indicate the measuring sites, abbreviations are described in the text. A detailed map of the area is given in Juen (2006) and Juen et al. (2007).

sum of all incoming (positive) and outgoing (negative) energy fluxes on the glacier surface and can be written as

$R+Q_{S}+Q_{L}+Q_{G}=F \quad\left[\mathrm{~W} \mathrm{~m}^{-2}\right]$.

$R$ is the net all-wave radiation, $Q_{S}$ and $Q_{L}$ are the turbulent fluxes of sensible and latent heat, $Q_{G}$ is the subsurface conductive and radiative heat flux and $F$ is the resulting energy flux at the surface. $F$ represents the energy used for melting, if the surface temperature $T_{S}=0^{\circ} \mathrm{C}$ and $F>0$. Although precipitation can fall as rain on the lower sections of the glaciers in the Cordillera Blanca (Juen, 2006), it is neglected as a possible energy source because precipitation intensities are weak and rain temperatures are close to $0^{\circ} \mathrm{C}$.

The Perúvian Andes belong to the outer tropics, which are characterised by one dry and one wet season (Kaser and Osmaston, 2002). During the dry season (May-September) specific humidity is low, and the vertical water vapour pressure gradient over the surface is generally positive downward, resulting in a negative $Q_{L}$. Sublimation occurs during most of the time, decreasing the energy available for melting drastically (Wagnon et al., 1999b), the reason being latent heat of sublimation $\left(L_{S}=2848 \mathrm{~kJ} \mathrm{~kg}^{-1}\right)$ is 8.5 -times higher than latent heat of fusion $\left(L_{M}=334 \mathrm{~kJ} \mathrm{~kg}^{-1}\right)$. Therefore, it is crucial to know how much ice sublimates from a tropical glacier, in order to quantify the surface energy balance, and thus the mass balance.

Few sublimation measurements have been carried out so far, probably due to the minor role of sublimation in the surface energy balance on well observed mid-latitude glaciers. On tropical glaciers only Wagnon et al. (1999a,b) carried out intensive research on sublimation. Near the long-term mean equilibrium line of Glaciar Zongo, Bolivia, they used lysimeters to directly measure sublimation and calculated the turbulent fluxes with the bulk method (see e.g. Garratt,
1992). They found that $Q_{L}$ is a major sink in the surface energy balance and undergoes a significant seasonal variation. Sublimation rates $\dot{S}=Q_{L} / L_{S}$ reach monthly means of $1.1 \mathrm{~kg} \mathrm{~m}^{-2} \mathrm{~d}^{-1}$ in the dry season, dropping to $0.3 \mathrm{~kg} \mathrm{~m}^{-2} \mathrm{~d}^{-1}$ in the wet season, which is comparable to mean sublimation rates on alpine glaciers on dry days in summer $\left(\dot{S} \approx 0.25 \mathrm{~kg} \mathrm{~m}^{-2} \mathrm{~d}^{-1}\right.$; Kaser, 1982). Cullen et al. (2007) used eddy covariance instrumentation to assess $Q_{L}$ during two days in the dry season on the summit of Kilimanjaro (East African inner tropics), obtaining $\dot{S}=1.44 \mathrm{~kg} \mathrm{~m}^{-2} \mathrm{~d}^{-1}$. Model results of Mölg and Hardy (2004) show longer-term mean sublimation rates on Kilimanjaro of $0.92 \mathrm{~kg} \mathrm{~m}^{-2} \mathrm{~d}^{-1}$.

The vertical mass balance profile model, named ITGG model, developed and applied for the mass balance and runoff studies in the Cordillera Blanca by the Innsbruck Tropical Glaciology Group (Juen, 2006) parameterises sublimation based on the measurements on Glaciar Zongo because of lack of data from the Cordillera Blanca. The Cordillera Blanca is influenced by the Intertropical Convergence Zone and Glaciar Zongo, which is situated $1300 \mathrm{~km}$ farther southeast $\left(16^{\circ} \mathrm{S}, 68^{\circ} \mathrm{W}\right)$, is characterised by more subtropical climate conditions. Therefore precipitation patterns are assumed to be different and the use of the Glaciar Zongo data to parameterise sublimation in the ITGG model for the Cordillera Blanca is not optimal. The findings of this study will be incorporated in future versions of the ITGG model.

The current study aims to (1) quantify sublimation rates on a glacier of the Cordillera Blanca in the dry season by direct measurements, (2) model the sublimation for different time scales, (3) improve the surface roughness parameterisation for tropical glaciers in the bulk method and (4) assess the way to parameterise sublimation in the ITGG model.

\section{Measurement site and methods}

As part of a field campaign in August 2005, sublimation was measured on the tongue of Glaciar Artesonraju (Fig. 1) at $8^{\circ} 58^{\prime} \mathrm{S}, 77^{\circ} 38^{\prime} \mathrm{W}$ in the northern part of the Cordillera Blanca. The areal extent of the glacier is $5.7 \mathrm{~km}^{2}$, reaching from Nevado Artesonraju (6025 m) down to the end of the short and distinct tongue at $4750 \mathrm{~m}$ (Juen, 2006; Winkler, 2007). The mean equilibrium line altitude is about $5150 \mathrm{~m}$. In 2005, the surface on many parts of the flat tongue showed an undulated structure (Fig. 2, left), with many penitentes, measuring a few centimeters to half a meter, and very deep cryoconite holes (partly more than $1 \mathrm{~m}$ ). Only sublimation (no melting) occurred during night-time and in the mornings, which is known to cause high surface albedo (Juen, 2006). This fact is supposed to be due to the sublimationinduced formation of distinct surface features such as penitentes, which favour multiple reflections of the incoming radiation as well as the settling of dirt in small-scale troughs. On most afternoons, melting got more and more dominant, 


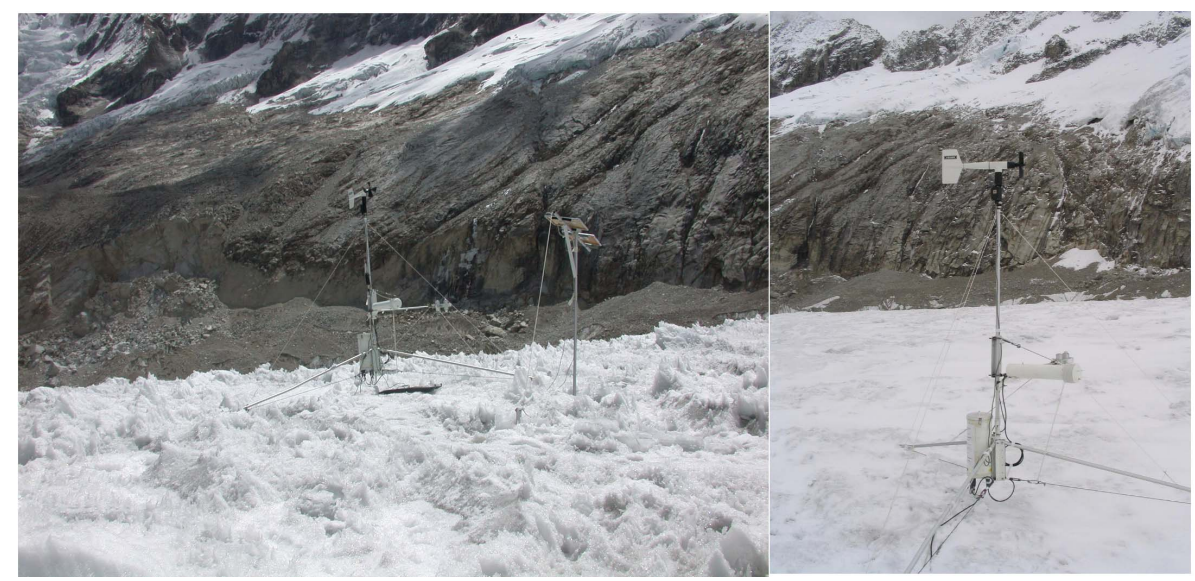

Fig. 2. The automatic weather station (SEBS) on the tongue of Glaciar Artesonraju in August 2005 when this study was made (left, photo: M. Winkler), and in July 2004 (right, photo: P. Wagnon). The difference in surface roughness is evident. In August 2005 a rough, undulated surface with many penitentes and cryoconite holes was dominant, in July 2004 the surface was much smoother.

and water was ponding in the hollows, which decreased the mean albedo of the tongue. The ponds froze again during the nights. All these features made the surface geometrically very rough and the surface albedo followed a clear diurnal cycle.

Since 2000, a stake network on Glaciar Artesonraju is maintained by the Unidad de Glaciología y Recursos Hídricos of the Perúvian Instituto National de Recursos Naturales (INRENA). An automatic weather station - here referred to as surface energy balance station (SEBS) - was installed in March 2004 at an altitude of $4810 \mathrm{~m}$ on the tongue and is maintained by the French Institute de Recherche pour le Développment (IRD) and the INRENA (Fig. 1 and Fig. 2). It measures the four components of the radiation balance (shortwave and longwave incoming and outgoing radiation), wind speed and direction, air temperature and relative humidity. Additionally, the Innsbruck Tropical Glaciology Group installed a radiation balance station (RBS) at $4750 \mathrm{~m}$ near the terminus in 2004, where all components of the radiation balance, as well as ablation (using a sonic ranging sensor) are measured. The RBS has a specially designed mounting device with a cardan-like joint to ensure that the radiation instruments maintain their horizontal position (Kaser et al., 2004). One automatic weather station next to and one opposite the glacier are also operated by the Innsbruck group since 2004 (Juen, 2006).

To measure sublimation ten transparent, cylindric plastic pots were used as lysimeters at two sites of different altitudes. One of them was at the SEBS, where six pots were used. The sublimation measurements from there can be linked directly to the SEBS data and the record of the ablation stake at the SEBS. The remaining four pots were used at $4890 \mathrm{~m}$, next to the highest stake of the ablation area (HAS). The sublimation measurements at the HAS can be related to the stake record at the HAS. Since the tongue of Glaciar Artesonraju is flat and walking distances are long, the $80 \mathrm{~m}$ difference in altitude between the two measuring sites was the maximum that could be reached within this specific field experiment. This is most probably too small to derive a characteristic vertical gradient in sublimation.

There was no visual difference in surface roughness between the measuring sites at the SEBS and the HAS in August 2005, but there can be differences on a seasonal or interannual scale. Figure 2 shows a comparison between the surface at the SEBS during the here presented sublimation measurements (left), and during five days when P. Wagnon carried out sublimation measurements with small scale plastic pot lysimeters between 21 and 27 July 2004 (cf. Table 1 and Fig. 3). Surface roughness was much lower in the dry season of 2004 than in the dry season of 2005. This difference is also reflected in the different measured sublimation rates. Consequently, P. Wagnon used smaller roughness lengths for modelling the surface energy balance for the 2004 period (cf. Sect. 3.2).

\subsection{Measuring procedure}

Holes of the size of the pots (diameter $=127 \mathrm{~mm}$, height $=85 \mathrm{~mm}$ ) were dug with an ice axe. The pots were filled with the excavated ice and weighed with an electronic balance. They were then placed in the holes ensuring that none of the rims were above the ice. So as to ensure the surface roughness wasn't changed. Still, there was no possibility of meltwater flowing into the pots. The pots were left in the ice for a certain time, then they were weighed again and placed back in the holes.

The evolving mass difference can be interpreted as the sublimated mass within the respective time span. For further processing of the data, arithmetic means of the mass 
Table 1. Daily totals of measured sublimation $\left[\mathrm{kg} \mathrm{m}^{-2} \mathrm{~d}^{-1}\right]$ during field studies in July 2004 (carried out by P. Wagnon) and in August 2005 (this study) at the SEBS and the HAS. The respective day numbers of the year (DOY) are given in brackets. Daily means of wind speed $v$ $\left[\mathrm{m} \mathrm{s}^{-1}\right]$, specific humidity $q\left[\mathrm{~g} \mathrm{~kg}^{-1}\right]$ and air temperature $T\left[{ }^{\circ} \mathrm{C}\right]$ from the SEBS are also given.

\begin{tabular}{|c|c|c|c|c|c|c|c|c|c|c|c|c|}
\hline $\begin{array}{c}2004 \\
\text { July }\end{array}$ & $\begin{array}{c}\text { SEBS } \\
\text { (smooth) }\end{array}$ & $v$ & $q$ & $T$ & $\begin{array}{c}2005 \\
\text { August }\end{array}$ & $\begin{array}{c}\text { SEBS } \\
\mathrm{P}^{-}\end{array}$ & $\begin{array}{c}\text { SEBS } \\
\mathrm{P}^{+}\end{array}$ & $\begin{array}{c}\text { HAS } \\
\mathrm{P}^{-}\end{array}$ & $\begin{array}{c}\text { HAS } \\
\mathrm{P}^{+}\end{array}$ & $v$ & $q$ & $T$ \\
\hline $21 \mathrm{st}(203)$ & 0.07 & 2.3 & 4.3 & -1.6 & 2nd (214) & 2.22 & & 3.57 & & 5.0 & 2.5 & -0.1 \\
\hline 22nd (204) & 0.42 & 2.9 & 4.0 & -1.9 & $3 r d(215)$ & 1.92 & & 1.79 & & 5.6 & 3.8 & -0.2 \\
\hline 23rd (205) & 0.64 & 3.0 & 3.7 & -1.6 & 4th (216) & 0.58 & & 0.94 & & 3.2 & 4.5 & -1.1 \\
\hline 24th (206) & 0.85 & 4.5 & 4.3 & -0.4 & 5th (217) & 0.98 & & 0.52 & & 4.4 & 5.2 & 0.9 \\
\hline \multirow[t]{9}{*}{ 27th (209) } & 0.84 & 4.1 & 4.5 & -0.9 & 6th (218) & 1.10 & & 0.93 & & 5.7 & 4.7 & -0.2 \\
\hline & & & & & 7th (219) & 0.86 & & 0.74 & & 4.7 & 4.4 & -0.6 \\
\hline & & & & & 9th (221) & 0.68 & 1.77 & 0.55 & 1.53 & 3.4 & 4.5 & -0.6 \\
\hline & & & & & 10th (222) & 1.24 & 3.37 & 0.67 & 1.83 & 3.5 & 4.5 & 0.1 \\
\hline & & & & & 11th (223) & 1.86 & 4.75 & 2.66 & 4.81 & 4.5 & 3.1 & -0.4 \\
\hline & & & & & 17th (229) & 2.97 & & & & 5.5 & 2.4 & -0.3 \\
\hline & & & & & 18th (230) & 2.13 & & & & 5.7 & 4.3 & -0.2 \\
\hline & & & & & 19th (231) & 0.95 & & & & 4.9 & 5.0 & 0.4 \\
\hline & & & & & 20th (232) & 0.35 & & & & 3.6 & 4.6 & -0.1 \\
\hline
\end{tabular}

changes of all available pots were calculated. As measurements affected by precipitation were excluded, an increase in mass can only be due to vapour deposition on the ice surface (hoar), which occurred only sometimes before dawn. Snow drift has never been observed during the measurements, mainly because of low wind speeds. Incidentally, with this method of measuring it is not possible to distinguish between sublimation, defined as the direct transition from ice to vapour, and evaporation following preceded melting. As there is no difference in energy consumption and mass transport between the two processes, henceforth the term sublimation will be used for both.

Two measurement series of sublimation were obtained. One 10-day series with measurements at the SEBS and the HAS with a resolution of $2 \mathrm{~h}$ during daytime, and one 5-day series measured at the SEBS with a resolution of $30 \mathrm{~min}$ during daytime. In late afternoon the pots were emptied, refilled, weighed, inserted into a new hole, and left untouched until the next morning. Hence, it was possible to calculate a mean night-time sublimation rate. Some gaps in the sublimation record occurred because of short showers or when the pots were renewed. During the 10-day series there is only one gap longer than $1 \mathrm{~h}$ in the record. It was caused by snowfall during the night from 8 to 9 August (day of year 220-221). During the 5-day series there is no gap longer than $1 \mathrm{~h}$. The 30-min resolution data provided by the SEBS, were without gaps during the whole period of investigation.

Not all parts of the glacier surface are well represented by the smooth ice in the pots. To overcome this problem, penitentes $(5-12 \mathrm{~cm})$ from the surroundings were broken off and put on top of half of the samples during three full days of the 10-day series. By doing this, the contact surface for turbulent exchange was increased approximately by $50-100 \%$.
Sublimation rates increased significantly, and measurements "without penitentes" $\left(\mathrm{P}^{-}\right)$had to be processed separately from the measurements "with penitentes" $\left(\mathrm{P}^{+}\right)$. The $\mathrm{P}^{-}$measurements can be considered as a lower and the $\mathrm{P}^{+}$measurements as an upper limit for sublimation on Glaciar Artesonraju during the dry season.

2.2 Assessing roughness lengths and surface emissivity with a process-based mass balance model

To solve Eq. (1) the surface energy balance module of the mass balance model described by Mölg et al. (2008) was used. It allows the calculation of $F$ using air temperature, relative humidity and wind speed as essential inputs. Shortwave incoming $\left(S W_{\text {in }}\right)$ and outgoing $\left(S W_{\text {out }}\right)$ as well as longwave incoming $\left(L W_{\text {in }}\right)$ and outgoing $\left(L W_{\text {out }}\right)$ radiation (the components of $R$ ) can be parameterised or measured. In this study $S W_{\text {in }}$ and $S W_{\text {out }}$ were taken from the SEBS record. The $L W_{\text {out }}$-record of the SEBS regularly exceeds $320 \mathrm{~W} \mathrm{~m}^{-2}$ during daytime, especially under clear-sky conditions when direct solar radiation warms the sensors. This corresponds to a black body temperature of more than $274 \mathrm{~K}$, which is not possible on ice. The comparison with the $L W_{\text {out }}$ data of the near RBS shows that the SEBS longwave radiation measurements suffer from the window heating offset (Obleitner and De Wolde, 1999). As the longwave data from the RBS seem to be representative for the sublimation measurement (nearly same altitude, same glacier surface structure, same shading effects) and do not exhibit this offset, the model inputs for $L W_{\text {in }}$ and $L W_{\text {out }}$ were taken from the RBS. The $S W_{\text {in }}$ records from both stations differ negligibly, but $S W_{\text {out }}$ data often differ considerably when the transient snow line is between the two stations. As sublimation was measured near 

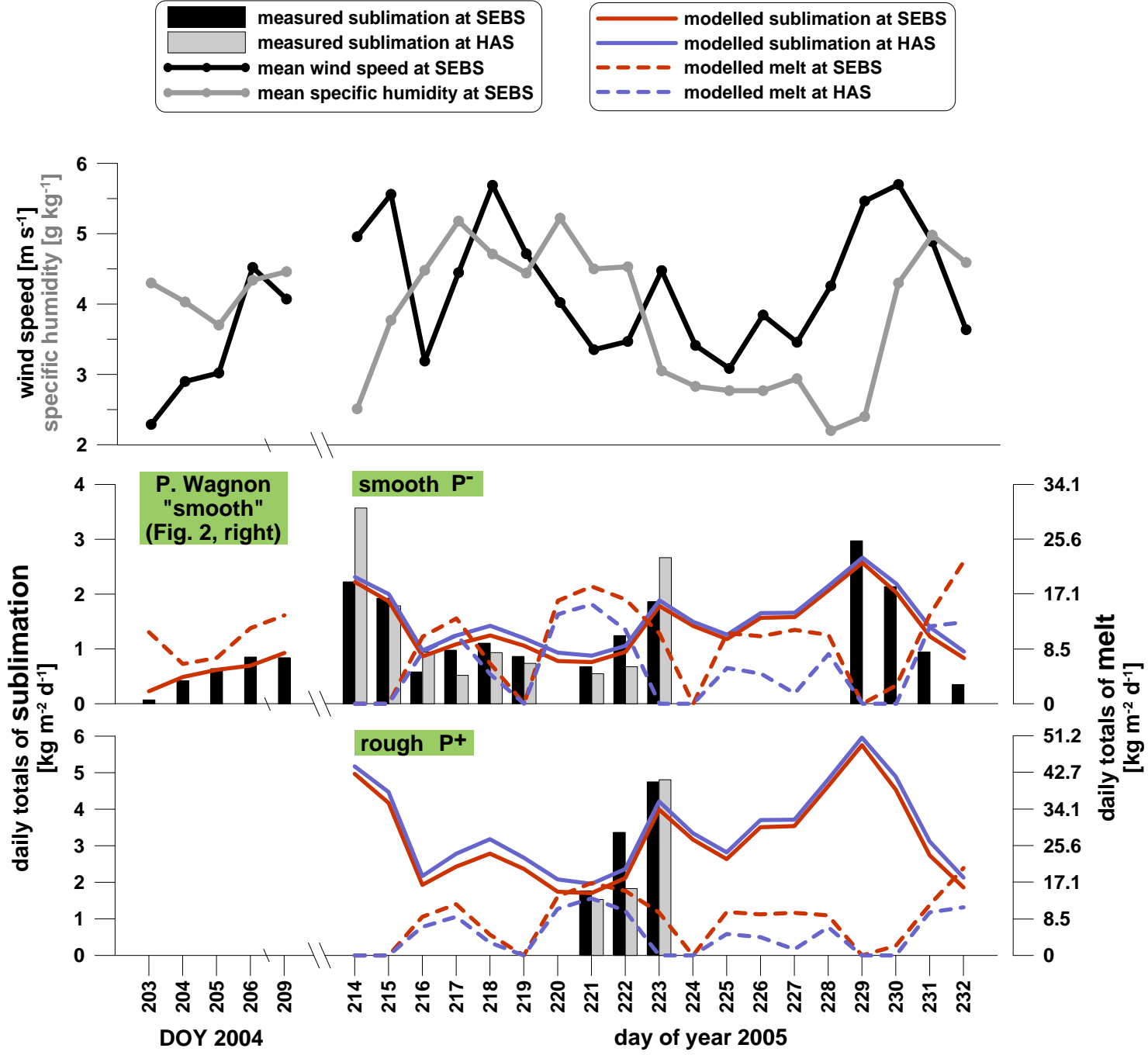

Fig. 3. Measured and modelled sublimation and modelled melting on Glaciar Artesonraju. On the middle and the lower graph daily totals of sublimation for the SEBS during four days in July 2004 (measured and modelled by P. Wagnon, model description in Wagnon et al. (1999a, 2001)), and for the SEBS and the HAS from August 2005 (this study) are shown. The uppermost graph depicts daily means of wind speed and specific humidity at the SEBS for the respective days. Note that days without bars are days without data from sublimation measurements, and not without sublimation. The axes corresponding to melting are on the right and are scaled by the factor $L_{S} / L_{M}=8.5$ compared to the axes for the sublimation values on the left (so energy needed for sublimation and melting are comparable). If the solid blue and red lines are above the dashed, sublimation consumes more energy than melting, and vice versa. The difference between smooth $\left(\mathrm{P}^{-}\right)$and rough $\left(\mathrm{P}^{+}\right)$ surface conditions is explained in the text.

the SEBS, shortwave radiation data was taken from there. $Q_{G}$ is solved from the temperature difference of the two uppermost model layers, and the turbulent fluxes $Q_{S}$ and $Q_{L}$ are calculated using the bulk method, which is based on the Monin-Obukhov similarity theory (e.g. Garratt, 1992). Within this theory, roughness lengths for momentum $\left(z_{m}\right)$, temperature and moisture are defined. The latter two are almost equal (Andreas, 1987) and Mölg and Hardy (2004) made no differentiation for Kilimanjaro. Both together are labelled as scalar roughness lengths and are signified by $z_{s}$ in the following.
Sublimation was measured with the lysimeters and total point ablation is known from the daily visits of the stakes at the SEBS and the HAS. The surface energy balance module should simulate both, sublimation and ablation, correctly. It was optimised by finding suitable roughness lengths, which can hardly be measured directly. The model was run in 30min time steps, and three criteria were defined for the best combination of the roughness lengths:

I The total sublimation of the measuring period should be modelled correctly. For this purpose, the cumulative sums of measured and modelled sublimation were 
calculated ( $\sum S_{\text {meas }}$ and $\sum S_{\text {mod }}$, respectively). For the most appropriate pair of $z_{m}$ and $z_{s}$ the relative difference $\Delta$, defined as

$\Delta=\frac{\sum S_{\text {meas }}-\sum S_{\text {mod }}}{\sum S_{\text {meas }}} \times 100 \%$

is minimal.

II The measured and calculated daily sublimation sums should agree. Therefore, the root mean square difference $\left(\mathrm{RMSD}_{1 d}\right)$ between the two was calculated. For the ideal combination of the roughness lengths $\mathrm{RMSD}_{1 d}$ is minimal.

III The high resolution measurements should be met by the model. For this purpose, the root mean square difference between the 30-min values of the model and the measurements (RMSD 30 min) was calculated and is minimal for the best pair of $z_{m}$ and $z_{s}$.

The emissivity coefficient of the ice surface $(\epsilon)$ was not measured directly. It was varied from 0.98 to 1 in the model. $\epsilon$ was set to the value leading to the best fit of the stake measurements and the modelled total ablation.

\subsection{The vertical mass balance profile model (ITGG model)}

In the Cordillera Blanca long-term records are only available for temperature and precipitation (1953 to 1996). The monthly resolution is, however, too low as input for complex mass balance models. Temperature-index models also fail, because air temperature variations cannot properly account for ablation on tropical glaciers (e.g. Kaser and Osmaston, 2002).

The ITGG model thus was designed to meet both, the limited data availability and the mass balance characteristics of tropical glaciers. It was extended from a vertical mass balance profile model (Kaser, 2001) by Juen (2006, 2007). In order to represent all humidity-related energy and mass fluxes they are parameterised by combining monthly precipitation from the Cordillera Blanca with short term energy balance information from Glaciar Zongo. One of these parameterisations concerns the distribution of the available energy for melting and sublimation, which is expressed by

$f=\frac{L_{S} S}{L_{S} S+L_{M} M}$,

where $f$ is the proportion of energy used for sublimation $S$ (in $[\mathrm{kg}]$ ) of the whole energy used for ablation (melting plus sublimation in [kg], $M+S$ ).

In this study the precipitation record of Llupa was used to assess monthly values of $f$. Llupa is situated near Huaraz at $3350 \mathrm{~m}$ a.s.1., $60 \mathrm{~km}$ south of Glaciar Artesonraju. The characteristics of precipitation in Llupa and on the glacier are assumed to be comparable, because both sites are west of the main Cordillera Blanca mountain range, the dominating meteorological divide (Kaser et al., 2003). The limits for $f$ (see below) in the ITGG model $\left(f_{\text {ITGG }}\right)$ were defined on the basis of Wagnon et al. (1999b), with small adjustments because Llupa has much lower maximum precipitation rates than Glaciar Zongo. $f_{\mathrm{ITGG}}=0.9$ was chosen for a very dry month with no precipitation, and $f_{\mathrm{ITGG}}=0.1$ for a wet month with $150 \mathrm{~mm}$ of precipitation. $f_{\text {ITGG }}$ of a certain month was calculated with Eq. (4) using the respective monthly precipitation $P$ and is valid for the whole glacier area.

$f_{\mathrm{ITGG}}=\frac{0.1-0.9}{150 \mathrm{~mm}} P+0.9$

For months with precipitation rates exceeding $150 \mathrm{~mm}$, the value was set to $P=150 \mathrm{~mm}$.

As Wagnon et al. (1999b) conducted their study on Glacier Zongo under slightly different climatic conditions (see Introduction), the reliability of the results gained by this approach is not optimal. One of the aims of the current study is to assess the parameterisation of $f_{\mathrm{ITGG}}$.

\section{Results and discussion}

\subsection{Measurement results}

Field measurements show that daily sublimation sums range from approximately $1-3 \mathrm{~kg} \mathrm{~m}^{-2} \mathrm{~d}^{-1}$ (mean: $\left.1.4 \mathrm{~kg} \mathrm{~m}^{-2} \mathrm{~d}^{-1}\right)$ for smooth $\left(\mathrm{P}^{-}\right)$to $2-5 \mathrm{~kg} \mathrm{~m}^{-2} \mathrm{~d}^{-1}$ (mean: $3.5 \mathrm{~kg} \mathrm{~m}^{-2} \mathrm{~d}^{-1}$ ) for rough $\left(\mathrm{P}^{+}\right)$conditions (Table 1 and Fig. 3).

Hourly maxima during daytime reach $0.28 \mathrm{~kg} \mathrm{~m}^{-2} \mathrm{~h}^{-1}$ for $\mathrm{P}^{-}$and $0.40 \mathrm{~kg} \mathrm{~m}^{-2} \mathrm{~h}^{-1}$ for $\mathrm{P}^{+}$, while night-time sublimation is generally reduced. Mean values are mainly lower than $0.05 \mathrm{~kg} \mathrm{~m}^{-2} \mathrm{~h}^{-1}$, with three nights reaching means of $0.1-0.15 \mathrm{~kg} \mathrm{~m}^{-2} \mathrm{~h}^{-1}$ for $\mathrm{P}^{-}$. For $\mathrm{P}^{+}$night-time sublimation is $0.05-0.2 \mathrm{~kg} \mathrm{~m}^{-2} \mathrm{~h}^{-1}$, so the difference to $\mathrm{P}^{-}$during night-time is smaller than during daytime. This is assumed to be due to generally lower wind speeds during the nights, causing lower turbulent fluxes (cf. Fig. 4). Generally, the $50-100 \%$ surface increase from $\mathrm{P}^{-}$to $\mathrm{P}^{+}$cannot describe the whole difference in sublimation. Also turbulence is enhanced by the increase in surface roughness from $\mathrm{P}^{-}$to $\mathrm{P}^{+}$, which yields higher sublimation rates.

An extensive error estimation of the sublimation measurements was done by Winkler (2007). The distribution function of the sublimation measurements is almost perfectly Gaussian. There are several sources of error, four of which have been quantified.

1. Inaccuracy of the balance: $\delta m_{*}=0.2 \mathrm{~g}$ (manufacturer information).

2. Too high values because of liquid water or hoar on the outer side of the pots or too low values because of mass loss due to the handling with the pots: $\delta m_{* *}=0.1 \mathrm{~g}$ (authors' estimation) 


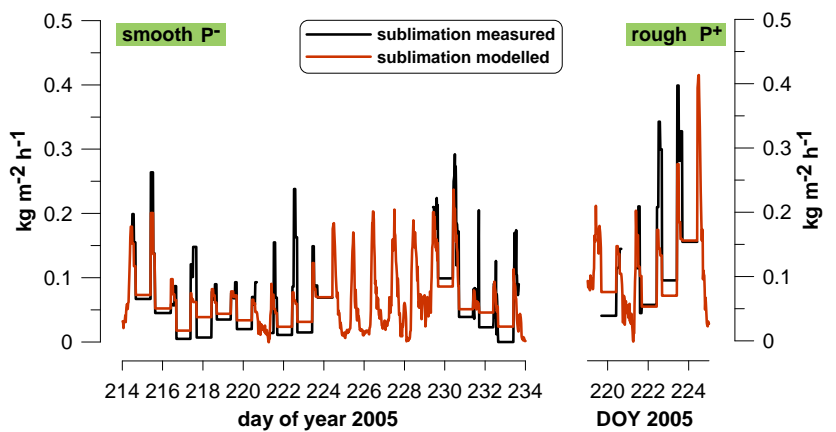

Fig. 4. Sublimation rates during the measuring series at the SEBS for $\mathrm{P}^{-}$(left) and $\mathrm{P}^{+}$(right). The model values (red) were obtained by taking $z_{m}=2.0 \mathrm{~mm}$ and $z_{s}=1.0 \mathrm{~mm}$ for $\mathrm{P}^{-}$and $z_{m}=20 \mathrm{~mm}$ and $z_{s}=10 \mathrm{~mm}$ for $\mathrm{P}^{+}$. They are averaged in correspondence with the temporal resolution of the measurements.

3. Inaccuracy of the cross section of the pots due to their plasticity: $\delta A=226 \mathrm{~mm}^{2}$ (authors' calculation).

4. Inaccuracy of the time measurement between to weighings of the same pot: $\delta t=2 \min$ (authors' estimation).

For the night-time measurements none of these errors was relevant because of the long time period and the considerably high mass differences of the pots between evening and morning. For this case, all the errors summed up to a relative error of only $2.6 \%$. During daytime $\delta m_{*}$ and $\delta m_{* *}$ turned out to be the most important sources of error. The 30-min resolution measurements during the 5-day period at the SEBS were affected most (here $\delta t$ played a role as well). For this period, all the errors propagated to a relative error of $27.7 \%$, because the time span between two measurements was short and sublimated mass was low. $6.9 \%$ was the relative error of the $2 \mathrm{~h}$-resolution measurements during the 10-day series, and the mean temporally weighted relative error in the sublimation rates for all day- and night-time measurements taken together was only $5.6 \%$.

Other sources of error, which have not been considered in the calculations above, are the possible disturbance of the subsurface fluxes by the pots, and the structural differences between the undisturbed ice at the surface and the excavated material in the pots. Both of them are very hard to quantify, but they are considered to be at the order of the four errors mentioned. The overall relative error, which sums up all mentioned sources of error, is not expected to exceed $10 \%$.

\subsection{Optimal results for $z_{m}, z_{s}$ and $\epsilon$}

After various model runs with different roughness length combinations, criterion (I) turned out to be most sensitive to them, and it finally led to the decision of which $z_{m}$ and $z_{s}$ to take. Using criterion (II) or (III) the model showed good results for many different rough-

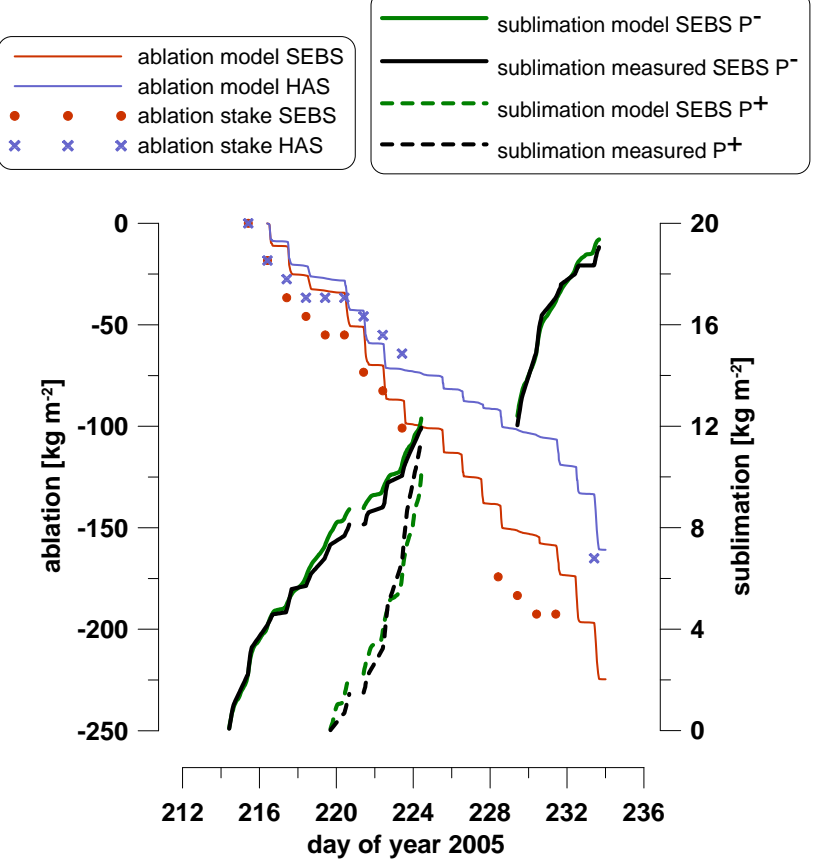

Fig. 5. Measured and modelled cumulative sublimation and ablation for the SEBS and the HAS. The gaps of the sublimation records refer to the gaps of the measurement series. Therefore, the sublimation values do not represent the actual sum of sublimated mass during the respective period. Note the different axis scaling, which was chosen to balance the figure graphically.

ness length combinations and therefore only played a minor role in decision making. Criterion (III) indicated that the correlation between model and measurement was better for $\mathrm{P}^{-}\left(\mathrm{RMSD}_{30 \mathrm{~min}}=0.021 \mathrm{~kg} \mathrm{~m}^{-2} \mathrm{~h}^{-1}\right)$ than for $\mathrm{P}^{+}\left(\mathrm{RMSD}_{30 \mathrm{~min}}=0.04 \mathrm{~kg} \mathrm{~m}^{-2} \mathrm{~h}^{-1}\right)$. For $\mathrm{P}^{-}$conditions $z_{m}=2.0 \mathrm{~mm}$ and $z_{s}=1.0 \mathrm{~mm}$ led to the smallest $\Delta$ for both sites $(\Delta<6 \%)$. The best solution for $\mathrm{P}^{+}$conditions at SEBS and HAS was $z_{m}=20.0 \mathrm{~mm}$ and $z_{s}=10.0 \mathrm{~mm}$, one order of magnitude greater than for $\mathrm{P}^{-}(\Delta<17 \%)$. Figure 5 shows the good agreement of measured and modelled cumulative sublimation (thick lines).

The ratio $z_{s} / z_{m}$ equals 0.5 in both cases, and so the surface counts as a "rough" surface according to Andreas (1987, his Fig. 8). The roughness lengths for $\mathrm{P}^{-}$are about the same as other authors found for glacier surfaces (e.g. Denby and Snellen, 2002; Cullen et al., 2007). For tropical Glaciar Zongo Wagnon et al. (1999a) do not distinguish between $z_{m}$ and $z_{s}$. They assess different roughness lengths for every month ranging from $2-5 \mathrm{~mm}$ during the wet season to 10 $30 \mathrm{~mm}$ during the dry season. These results correspond well with the values for $\mathrm{P}^{-}$and $\mathrm{P}^{+}$conditions found in this study.

In July 2004, when P. Wagnon measured sublimation on Glaciar Artesonraju for five days, he also modelled the surface energy balance using a roughness length of $0.3 \mathrm{~mm}$. 


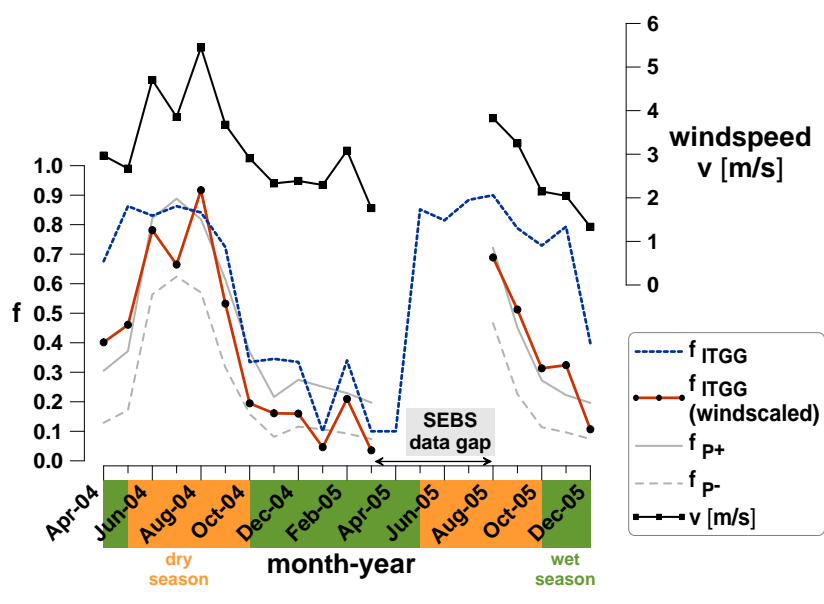

Fig. 6. Differently determined monthly values of $f$ between April 2004 and December 2005. The uppermost graph refers to the right $\mathrm{y}$-axis and shows the mean monthly wind speed $(v)$, measured at the SEBS.

This seems to be reasonable as surface features were much smoother than in August 2005 (see Fig. 2). The results of his measurements and the modelling are shown in Table 1 and Fig. 3, and a model description is given in Wagnon et al. (1999a, 2001).

$\epsilon$ is a very sensitive parameter for deriving $T_{S}$ from $L W_{\text {out }}$ measurements. (Sensitivity studies showed that for the RBS data of 2005 a $1 \%$-change from $\epsilon=1$ to $\epsilon=0.99$ results in melting conditions $\left(T_{S}=0^{\circ} \mathrm{C}\right)$ during $59 \%$ of the time, instead of only $37 \%$.) $\epsilon=0.998$ turned out to be best for modelling the ablation at the SEBS, $\epsilon=0.999$ for the HAS. Figure 5 shows the modelled total ablation (thin lines). The agreement with the stake records is acceptable, considering that the reading accuracy of the stakes may be as large as $1 \mathrm{~cm}$, which corresponds to about $9 \mathrm{~kg} \mathrm{~m}^{-2}$ of ablation.

3.3 Results for sublimation and melting from the processbased model

The high resolution model results for the sublimation rates are shown in Fig. 4 (red lines). In contrast to the measurements, the modelled values have no gaps. The shape of the daily cycle (low values during night-time and high values during daytime) is reproduced well by the model, but amplitudes are often underestimated. Possibly, the stability correction used in the model (see Mölg and Hardy, 2004) is not accurate enough during stable night-time layering or the amplitude of the measured $T_{S}$ (which is a model input) is too small. On a daily timescale these uncertainties balance to a large extent (Fig. 3).

Daily melting rates vary at least as much as daily sublimation rates (Fig. 3). During the field campaign there were days with no melting at all, and others with melting rates of more than $20 \mathrm{~kg} \mathrm{~m}^{-2} \mathrm{~d}^{-1}$. This stands in good agreement with the observation of days with hardly any melting and days with extensive meltwater ponding on the flat parts of the surface. On $60 \%$ of the days more energy is consumed by sublimation than by melting under $\mathrm{P}^{-}$conditions. When penitentes are developed $\left(\mathrm{P}^{+}\right)$, daily melting rates are even decreased by $10-12 \%$ and sublimation is doubled. Normally more than twice of the energy used for melting goes into sublimation at this point.

Figure 3 and Table 1 also show the daily means of wind speed $v$ and specific humidity $q$. There is a striking correlation between measured sublimation rates and the combination of $v$ and $q$. High sublimation corresponds well with low specific humidity (DOY 214, 215, 223, and 229), especially if wind speeds are relatively high (DOY 214, 215, 229). On the other hand, relatively high specific humidity in combination with low wind speeds (DOY 203-205, 216, 221, 222, and 232) causes low sublimation. Daily means of air temperature alone cannot explain sublimation at all (see Table 1).

To assess $f$ on a monthly scale, the surface energy balance was modelled from April 2004 to March 2005 and from August 2005 to December 2005 (17 months). $f$ is very sensitive to the change of surface temperature $\left(T_{S}\right)$ from $0^{\circ} \mathrm{C}$ to subfreezing, i.e. over the diurnal cycle. Generally, at $T_{S}=0^{\circ} \mathrm{C}, f$ is high, when sublimation is high. For $T_{S}<0^{\circ} \mathrm{C}$ no melting is possible and $f$ is always maximal, even though sublimation rates are very low.

Monthly values of $f$ show a distinct seasonality with high values during the dry season and low values during the wet season (Fig. 6, gray lines). $f \geq 0.4$ only occurred from June to September, and it is always higher for $\mathrm{P}^{+}$than for $\mathrm{P}^{-}$conditions, because higher roughness increases turbulence which enhances sublimation. Penitentes and surface roughness are normally higher in the dry season than in the wet season. Respectively, representative values of $f$ for the whole ablation area of Glaciar Artesonraju are probably most realistic, when taking the $\mathrm{P}^{-}$values in the wet season $\left(f_{P^{-}} \approx 0.1\right)$ and the $\mathrm{P}^{+}$ values in the dry season $\left(f_{P^{+}} \geq 0.7\right)$.

\subsection{Results for the ITGG model}

Like the monthly $f$-values calculated with the process-based mass balance model $\left(f_{P^{-}}\right.$and $\left.f_{P^{+}}\right), f_{\mathrm{ITGG}}$ also shows a seasonal variation (Fig. 6). Absolute values of $f_{\text {ITGG }}$ during the core dry season of 2004 and the wet season are similar to the mass balance model. The biggest differences occur during the transition periods in April and May 2004 and from September to November 2005. According to $f_{\text {ITGG }} 70-90 \%$ of the available energy goes into sublimation during these periods, whereas $f_{P^{-}}$and $f_{P^{+}}$only range from $0.1-0.5$.

This is partly because the limits for $f_{\mathrm{ITGG}}(0.1$ and 0.9 , respectively) are based on Glaciar Zongo data (Wagnon et al., 1999b), where rapid transitions from clear-sky conditions to shower-like precipitation are more likely than in the Cordillera Blanca. During months with low mean air humidity, when sublimation is enhanced and $f$ is high, notable 
precipitation might fall on Glaciar Zongo. In the Cordillera Blanca, when monthly precipitation exceeds a certain threshold, mean air humidity is supposed to be generally high resulting in low $f$-values. This explains, to some extent, why $f_{\text {ITGG }}$, which is biased by the Glaciar Zongo conditions, is higher than $f_{P^{-}}$and $f_{P^{+}}$during the wet season. Moreover, $f_{\text {ITGG }}$ is designed to represent the whole glacier, while $f_{P^{-}}$ and $f_{P^{+}}$are modelled for a point on the tongue. In reality there is a high spatial variability in surface roughness.

Sublimation and $f$ are not only humidity-related, but also wind speed plays a particular role in forcing the turbulent fluxes. Figure 6 shows the monthly mean wind speed $(v)$ at the SEBS. There is a slight seasonality as well, with higher values during the dry season and lower values during the wet season. Hence, a simple approach including wind speed in the ITGG parameterisation looks as follows

$f_{\mathrm{ITGG}}($ windscaled $)=f_{\mathrm{ITGG}} \times \frac{v}{5 \mathrm{~m} \mathrm{~s}^{-1}}$.

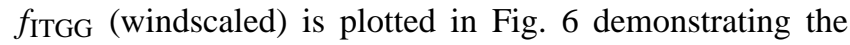
strong agreement with $f_{P^{-}}$and $f_{P^{+}}$. Unfortunately, there is no long term record for wind speed available in the Cordillera Blanca, but the results shown in Fig. 6 are encouraging. Further studies may, e.g., explore downscaled reanalysis wind data for a better parameterisation of $f_{\mathrm{ITGG}}$.

\section{Conclusions}

The importance of sublimation for the surface energy and mass balance on tropical glaciers during the dry seasons was confirmed by direct measurements using simple plastic pots as lysimeters. Low specific humidity and moderate wind speeds efficiently remove water vapour from the viscous sublayer over the glacier, resulting in a high turbulent latent heat and moderate mass flux from the surface. As latent heat of sublimation is 8.5-times higher than latent heat of fusion this process cools the surface and reduces the energy available for melting very efficiently and, as a net effect, decreases ablation.

Surface roughness strongly increases turbulence, surface area and, thus, sublimation. During the time of investigation the tongue of Glaciar Artesonraju was well-structured, showing many penitentes. A differentiation between rough and smooth conditions was necessary and led to the definition of a lower and an upper limit of sublimation $\left(\mathrm{P}^{-}, \mathrm{P}^{+}\right)$. In order to extend the measurement series from 15 days to 17 months, a process-based mass balance model was optimised by the sublimation measurements. The parameterisation of surface roughness on tropical glaciers could be reassessed and results from other studies were verified. Surface roughness lengths used in the bulk method (for momentum and scalars) are variable within one order of magnitude, depending on surface structure.

Sublimation consumes $10-15 \%$ of the total energy available for ablation during the wet season and 60-90\% dur- ing the dry season. These results confirm the assumptions made for the lower complexity mass balance model ITGG, which is motivating because within the framework of the ITGG only precipitation records were used to parameterise the mentioned seasonality in sublimation. During the transition periods between dry and wet seasons further improvements could be reached by including wind speed in this parameterisation.

Acknowledgements. We highly acknowledge IRD Great Ice for supporting the French Observatory GLACIOCLIM, in whose framework the surface energy balance measurements on Artesonraju were developed. Robert Gallaire (IRD, Lima) and Marco Zapata an his team of the INRENA in Huaráz, Perú, are acknowledged for their efforts to maintain the instruments and the stake network on Glaciar Artesonraju. Hector Oropeza and his brothers once more provided essential support during the field work, and Alcides $(\dagger)$ and Franzisca Ames' assistance at their hostal was again substantial for the field trip. This work has been facilitated by the Austrian Science Foundation (FWF) grants number P16113-N06 and P20089-N10.

Edited by: J. O. Hagen

\section{References}

Andreas, E. L.: A theory for scalar roughness and the scalar transfer coefficient over snow and sea ice, Bound.-Layer Meteor., 38, 159-184, 1987.

Cullen, N. J., Mölg, T., Kaser, G., Steffen, K., and Hardy, D. R.: Energy-balance model validation on the top of Kilimanjaro, Tanzania, using eddy covariance data, Ann. Glaciol., 46, 227-233, 2007.

Denby, B. and Snellen, H.: A comparison of surface renewal theory with the observed roughness length for temperature on a melting glacier surface, Bound.-Layer Meteor., 103, 459-468, 2002.

Garratt, J. R.: The Atmospheric Boundary Layer, Cambridge Univ. Press, New York, 1992.

Hoinkes, H.: Methoden und Möglichkeiten von Massenhaushaltsstudien auf Gletschern, Z. Gletscherk. Glazialgeol., 6, 37-90, 1970

Juen, I.: Glacier mass balance and runoff in the tropical Cordillera Blanca, Perú, Ph.D. thesis, Institute of Geography, University of Innsbruck, Austria, 2006.

Juen, I., Kaser, G., and Georges, C.: Modelling observed and future runoff from a glacierized tropical catchment (Cordillera Blanca, Perú), Global Planet Change, 59, 37-48, 2007.

Kaser, G.: Measurements of Evaporation from Snow, Arch. Met. Geoph. Biokl., Ser. B, 30, 333-340, 1982.

Kaser, G.: A review of the modern fluctuations of tropical glaciers, Global Planet Change, 22, 93-103, 1999.

Kaser, G.: Glacier-climate interaction at low-latitudes, J. Glaciol., 47, 195-204, 2001.

Kaser, G. and Osmaston, H.: Tropical glaciers, International Hydrology Series, UNESCO and Cambridge University Press, 2002.

Kaser, G., Juen, I., Georges, C., Gómez, J., and Tamayo, W.: The impact of glaciers on the runoff and the reconstruction of mass 
balance history from hydrological data in the tropical Cordillera Blanca, Perú, J. Hydrol., 1-4, 130-144, 2003.

Kaser, G., Juen, I., and Giegele, T.: An AWS mounting device which mechanically adjusts itself to changing glacier surface conditions, in: Automatic weather stations on glaciers, edited by: Oerlemans, J. and Tijm-Reijmer, C. H., pp. 59-62, 2004.

Kuhn, M.: The response of the equilibrium line altitude to climate fluctuations: theory and observations, in: Glacier fluctuations and climatic change, edited by Oerlemans, J., Glaciology and quaternary geology, pp. 407-417, Kluwer Academic Publishers, 1989.

Mölg, T. and Hardy, D. R.: Ablation and associated energy balance of a horizontal glacier surface on Kilimanjaro, J. Geophys. Res., 109, D16104, doi:10.1029/2003JD004338, 2004.

Mölg, T., Cullen, N., Hardy, D. R., Kaser, G., and Klok, L.: Mass balance of a slope glacier on Kilimanjaro and its sensitivity to climate, Int. J. Climatol., 28, 881-892, doi:10.1002/joc.1589, 2008.
Obleitner, F. and De Wolde, J.: On intercomparison of instruments used within the Vatnajökull glacio-meteorological experiment, Bound.-Layer Meteor., 92, 27-37, 1999.

Wagnon, P., Ribstein, P., Francou, B., and Pouyand, B.: Annual cycle of energy balance of Zongo Glacier, Cordillera Real, Bolivia, J. Geophys. Res., 104, 3907-3923, 1999a.

Wagnon, P., Ribstein, P., Kaser, G., and Berton, P.: Energy balance and runoff seasonality of a Bolivian glacier, Global Planet Change, 22, 49-58, 1999b.

Wagnon, P., Ribstein, P., Francou, B., and Sicart, J. E.: Anomalous heat and mass budget of Glaciar Zongo, Bolivia, during the 1997/1998 El Nino year, J. Glaciol., 47, 21-28, 2001.

Winkler, M.: Die Rolle der Sublimation in der Energie- und Massenbilanz des tropischen Glaciar Artesonraju, Master's thesis, Institute of Meteorology and Geophysics, University of Innsbruck, Austria, 2007. 